\title{
Lumbar disk herniation presented with cauda equina syndrome in a pregnant woman
}

\author{
Tayfun Hakan \\ Haydarpaşa Numune Teaching and Research Hospital, Neurosurgery Clinic, 34668 Üsküdar, İstanbul, Turkey
}

\section{ABSTRACT}

Despite low back pain being common in pregnancy, cauda equina syndrome is rare. Misdiagnosis and delay in treatment may cause neurological sequelae including urinary and fecal incontinence, sexual dysfunction in patients. A case of cauda equina syndrome in a pregnant woman at 25 -week gestation is presented here. The patient underwent an emergency, standard lumbar microdiscectomy under general anesthesia on prone position. Neither the patient nor the baby had any complication related to surgery.

Key words: Cauda equina syndrome, lumbar disc herniation, lumbar discectomy, magnetic resonance imaging, pregnancy

\section{Introduction}

Mechanical and positional stresses of pregnancy are the primary inciting factors that cause lumbosacral pain accompanying gestation. Although low back pain is common, fortunately, the incidence of symptomatic lumbar disk herniation in pregnancy is about $1: 10,000{ }^{[1]}$ Cauda equina syndrome from lumbar disk herniation is a very serious problem that characterized with bilateral sciatica, bilateral weakness of legs especially below the knees, saddle hypesthesia and/or anesthesia and incontinence. ${ }^{[2]}$ Although there are cases of lumbar disk herniation in pregnancy, reports about the association of these two conditions - cauda equina syndrome secondary to the disk herniation and pregnancy - are very few. ${ }^{[3-5]}$ As clinicians we should be aware of this condition because a potential misdiagnosis and delay in treatment may be ended with neurological sequelae.

\section{Case Report}

A 34-year-old woman presented at 25-week gestation in her third pregnancy with a 2-day history of low

\begin{tabular}{|l|l|}
\hline \multicolumn{2}{|c|}{ Access this article online } \\
\hline Quick Response Code: & Website: \\
\hline & www.ruralneuropractice.com \\
\cline { 2 - 2 } & \\
\hline
\end{tabular}

back pain, numbness in her buttocks, urinary and fecal incontinence. Neurological examination revealed bilateral positive sciatic nerve stretch, saddle paraesthesia and diminished anal tone. Magnetic resonance imaging (MRI) displayed a large extruded disk fragment at L5-S2 level [Figure 1]. After evaluation of the patient by obstetrician and anesthesiologist, an emergency, standard right L5-S1 partial hemilaminotomy and microdiscectomy performed under general anesthesia on prone position. The postoperative period was uneventful. She discharged on the fourth postoperative day and delivered a healthy infant at term. At 6-month followup, although bowel and bladder were nearly normal, the reduced sensation in the sacral area was continuing.

\section{Discussion}

Cauda equina syndrome is a serious problem that should be managed as an emergency condition in patients whether they are pregnant or not. This study reports that the management of cauda equina secondary to the lumbar disk herniation during pregnancy can be done successfully.

Hormonal changes and mechanical strain emerge as backache which is a very common symptom in late pregnancy. If a pregnant woman has a severe back and/ or leg pain lumbar disk prolapse should be considered ${ }^{[6]}$ not be evaluated as a normal occurrence. To avoid any misdiagnosis and delay, a rectal examination with sensory examination of the sacral area recommended

\section{Address for correspondence:}

Dr. Tayfun Hakan, Haydarpaşa Numune Teaching and Research Hospital, Neurosurgery Clinic, 34668 Üsküdar, İstanbul, Turkey.

E-mail: tayfunhakan@yahoo.com 

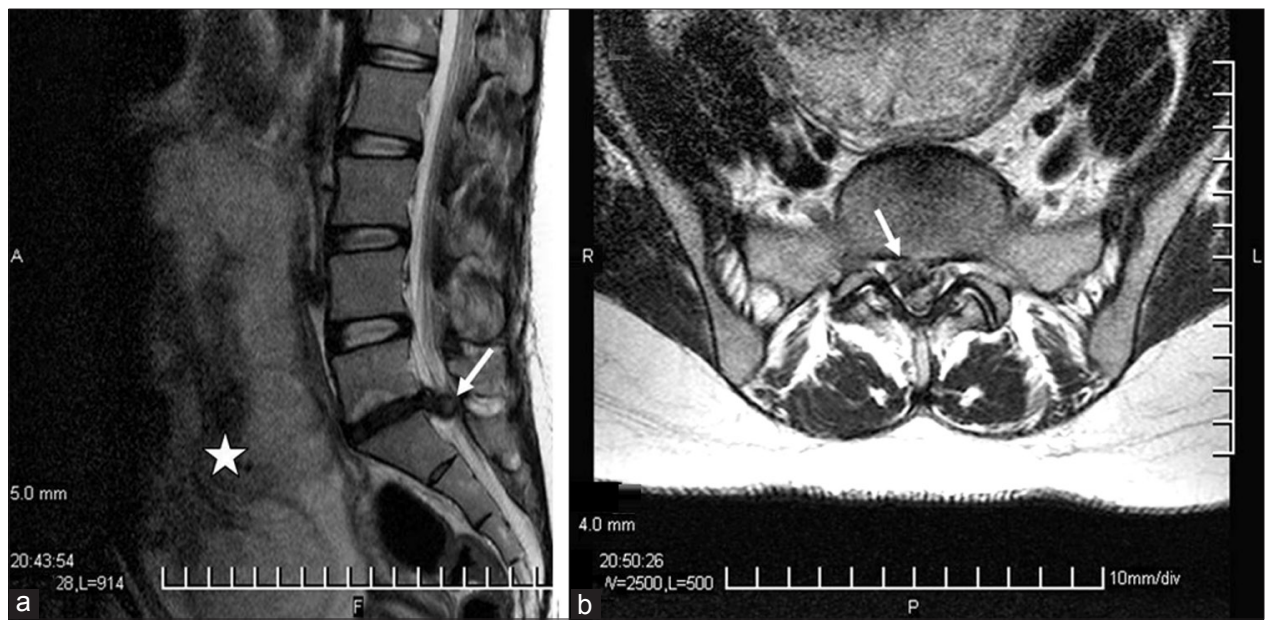

Figure 1: (a) Sagittal T2 weighted magnetic resonance imaging demonstrating a large sequestered disk fragment at L5-S1 level causing cauda equina compression (white arrow), the enlarged uterus with fetus (asterisk). (b) Axial T2 weighted MRI demonstrating a large sequestered centralright paracentral disk fragment at L5-S1 level (white arrow)

in the patients having a history of urinary incontinence and saddle anesthesia. ${ }^{[7]}$

An imaging examination is required in these patients because cauda equine syndrome is a clinical diagnosis. ${ }^{[4,7]}$ Imaging not only confirms the diagnosis but also reveals the level of disk herniation prior surgery. MRI (magnetic resonance imaging) is an useable diagnostic tool in pregnant woman; it permits a detailed spinal examination without the ionizing effects of $x$-ray and its acknowledged biological risk to the developing fetus. ${ }^{[1,3,5]}$ Despite the safety of MRI during pregnancy being not proven, there is no report stressing that the use of clinical MR procedures during pregnancy produces adverse effects.

Most of these patients can be easily treated with conservative modalities. Surgical management may require in case of severe intractable back pain and leg pain unresponsive to conservative management, progressive neurological deficits or cauda equina syndrome in the patients. ${ }^{[3,5]}$ Motor weaknesses in legs, severe pain, urinary and/or gaita incontinence and sexual dysfunction are the sign and symptoms of cauda equina. Cauda equina syndrome may develop in a few hours. Especially in the presence of neurological deficit as cauda equina syndrome, emergency decompression is recommended to avoid permanent neurological sequelae in every gestational week of the pregnant woman. ${ }^{[3,5]}$ Cauda equina syndrome secondary to lumbar disk compression may be reversible if it can be managed acutely. ${ }^{[8]}$ Timothy et al..$^{[7]}$ reported that urinary and fecal incontinence were persisted in a primigravida for delaying surgical treatment. In the presented case, the patient had a two day history of cauda equine syndrome and sphincter dysfunctions disappeared rapidly following surgery. Even though an emergency decompression was made following diagnosis, reduced sensation in the sacral area was continued for 6 months.

MRI, ${ }^{[1]}$ anesthesia ${ }^{[9]}$ and surgical lumbar disk excision is not contraindicated in any stage of gestation. ${ }^{[3,5]}$ Brown et al. ${ }^{[10]}$ performed a disk excision for cauda equina syndrome secondary to a massive lumbar disk herniation and a caesarian section for term pregnancy during the same anesthesia. They thought that epidural injection combined with the stress of repeated Valsalva maneuvers for vaginal delivery could increase intratechal pressure. So they performed cesarean delivery under general anesthesia followed an immediate disk excision.

Abou-Shameh et al. ${ }^{[6]}$ pointed that an additional care should be taken for the position of the pregnant woman during surgery for excessive pressure can cause preterm delivery. İyilikçi et al. ${ }^{[9]}$ recommend a left lateral decubitis position to avoid the risk of aortacaval compression after the second trimester. During the third trimester, a right lateral decubitis position should not be used due to the risk of aortacaval compression of the inferior vena cava. Gupta et al..$^{[8]}$ reported that they preferred a cesarean section prior to discectomy since the prone position for discectomy was difficult to achieve with a 35-week gravid uterus. Lumbar disk excision can be done safely via a standard surgical ${ }^{[3,4,6,7,9]}$ or endoscopic ${ }^{[5]}$ technique during pregnancy. We used the standard microsurgical discectomy technique in prone position in this case. No complication was seen related with surgery and/or patient with her baby.

In conclusion, although low back pain is common, detailed physical examination with MR scanning should 
be done in the case of sudden incapacitating back or leg pain during pregnancy. If there is progressive neurological deficit and/or signs and symptoms of cauda equine syndrome, it is essential to make decompressive lumbar disk surgery for avoiding neurological sequelae.

\section{References}

1. LaBan MM, Rapp NS, von Oeyen P, Meerschaert JR. The lumbar herniated disk of pregnancy: A report of six cases identified by magnetic resonance imaging. Arch Phys Med Rehabil 1995;76:476-9.

2. Shapiro S. Cauda equina syndrome secondary to lumbar disc herniation. Neurosurgery 1993;32:743-7.

3. Brown MD, Levi AD. Surgery for lumbar disc herniation during pregnancy. Spine (Phila Pa 1976) 2001;26:440-3.

4. Curtin P, Rice J. Cauda equina syndrome in early pregnancy: A case report. Acta Obstet Gynecol Scand 2007;86:758-9.

5. Kim HS, Kim SW, Lee SM, Shin H. Endoscopic discectomy for the cauda equina syndrome during third trimester of pregnancy. J Korean Neurosurg Soc 2007;42:419-20.

6. Abou-Shameh MA, Dosani D, Gopal S, McLaren AG. Lumbar discectomy in pregnancy. Int J Gynaecol Obstet 2006;92:167-9.

7. Timothy J, Anthony R, Tyagi A, Porter D, van Hille PT. A case of delayed diagnosis of the cauda equina syndrome in pregnancy. Aust N Z J Obstet Gynaecol 1999;39:260-1.

8. Gupta P, Gurumurthy M, Gangineni K, Anarabasu A, Keay SD. Acute presentation of cauda equina syndrome in the third trimester of pregnancy. Eur J Obstet Gynecol Reprod Biol 2008;140:279-81.

9. Iyilikçi L, Erbayraktar S, Tural AN, Celik M, Sannav S. Anesthetic management of lumbar discectomy in a pregnant patient. J Anesth 2004;18:45-7.

10. Brown MD, Brookfield KF. Lumbar disc excision and cesarean delivery during the same anesthesia. A case report. J Bone Joint Surg Am 2004;86A:2030-2.

How to cite this article: Hakan T. Lumbar disk herniation presented with cauda equina syndrome in a pregnant woman. J Neurosci Rural Pract 2012;3:197-9.

Source of Support: Nil. Conflict of Interest: None declared. 